\title{
STUDY OF THE MECHANICAL LAW AND \\ DISTURBANCE-RESPONSE CHARACTERISTICS DURING DEEP-FILLING MINING
}

\section{ŠTUDIJA ZAKONOV MEHANIKE IN KARAKTERISTIKE MOTENJ ODZIVA PRI ZASIPAVANJU MED PODZEMNIM RUDARJENJEM}

\author{
Keping Zhou ${ }^{1,2}$, Zhichao $\mathrm{Li}^{1,2}$, Rugao Gao ${ }^{1,2^{*}}$ \\ ${ }^{1}$ College of Resources and Safety Engineering, Central South University, Changsha 410083, China \\ ${ }^{2}$ Hunan Key Laboratory of Mineral Resources Exploitation and Hazard Control for Deep Metal Mines, Changsha 410083, China
}

Prejem rokopisa - received: 2018-12-08; sprejem za objavo - accepted for publication: 2019-03-11

doi: $10.17222 /$ mit.2018.261

\begin{abstract}
The study is aimed at exploring the dynamic and static combined mechanical response characteristics of backfill in deep mining. The mechanical properties of the rock mass of the mine and backfill are tested by laboratory experiments. Based on the SEM analysis results, a stress-strain damage constitutive model of the backfill is established, laying a foundation for the numerical inversion of the deep-stress environment. A self-defined function is applied to introduce a damage constitutive model of the backfill by the method of dynamic renewal elastic modulus in order to analyze the regional model. Through the analysis of mining-induced stress in the high stress and mechanical response law of the backfill in blasting coupling, the attenuation curve and the formula of the peak stress and the vibration velocity changing with denotation distance is formed. Finally, the propagation law of the stress waves in rock mass and backfill in the process of backfilled deep mining is obtained. The research is of certain value in guiding deep mining engineering.

Keywords: backfill mechanics, constitutive model, dynamic response, vibration velocity attenuation

Avtorji so raziskovali značilnosti kombinacije statičnega in dinamičnega odziva mehanskih karakteristik zasipavanja med podzemnim rudarjenjem. Mehanske lastnosti rudne jalovine in zasipavanje so testirali s pomočjo laboratorijskih preizkusov. Na osnovi rezultatov SEM analiz so razvili konstitutivni napetostno-deformacijski porušitveni model za zasipavanje, ki je temelj za numerično inverzijo napetostnega okolja globoko pod zemljo. Uporabili so funkcijo, ki so jo sami definirali za uvedbo konstutivnega porušitvenega modela zasipavanja $\mathrm{z}$ metodo dinamične obnove elastičnega modula za analizo lokalnega modela. Med analizo z rudarjenjem (odkopavanjem) induciranih napetosti med visoko napetostnim in mehanskim odzivom so na osnovi zakonov zasipavanja v povezavi $\mathrm{z}$ detonacijami (sunki zaradi razstrelitev) razvili krivulje popuščanja (slabenja) in enačbo za maksimalno (vršno) napetost glede na spremembe vibracijskih hitrosti in detonacijske razdalje. Nazadnje so avtorji izdelali še zakon napredovanja napetostnih valov $\mathrm{v}$ skalovju in zasipu v procesu podzemnega rudarjenja. Po njihovem mnenju ima raziskava določeno uporabno vrednost za vodenje rudarskega inženiringa med rudarjenjem globoko pod zemljo.

Ključne besede: mehanika zasipavanja, konstitutivni model, dinamični odziv, slabenje vibracijske hitrosti
\end{abstract}

\section{INTRODUCTION}

Over the years, backfill mining has been increasingly recognized and praised in the optimization of resource-utilization schemes due to its great advantages in terms of resource-recovery utilization rate and environmental protection. In deep mining, in order to maintain the stability of the stope and reduce the depletion caused by the mixing of the backfill in pillar robbing, it is necessary to carry out complete research on the mechanical properties of the backfill., ${ }^{1,2}$ The properties of the backfill aggregate, cement-tailing ratio (CTR), moisture content and curing time can be considered as the internal causes of the mechanical properties of the backfill. Unlike concrete, the backfill is a kind of multi-phase composite material with cracks, fractures, bubbles, holes, etc. which has lower intensity, and the deformation process of the backfill medium is not com-

*Corresponding author's e-mail:

gaorgcsu@163.com pletely brittle. ${ }^{3-5}$ Currently, there are only a few studies at home and abroad on the internal micro cracking of mine cemented backfill and various mechanical behaviors caused by the micro cracking, and there is also a lack of research on the mechanical response mechanism of backfill in a complex environment. Although some criteria for the instability failure of the backfill have been set, they are not sufficiently perfect. Therefore, research on the mechanical properties of backfill materials should be shifted from conventional mechanics to a parameterdegradation mechanism and composite mechanics.

In recent years, the development of the mesoscopic damage theory is between the theory of continuous damage mechanics and the theory of habitual damage. The problem is that the definition and determination of the current damage variables are not uniform, which needs further analysis and discussion. When considering practical issues in engineering, there is often a lack of research on the damage mechanism of the backfill parameters. Most scholars focus on the static mechanical 
properties of the backfill, but in actual mining, highspeed dynamic loads are often accompanied, such as blasting and rock bursting. The damage process of rock pillars is extremely complicated. In backfill mining, shock waves are first generated in the rock, then rapidly attenuate and finally gradually decay into stress waves. The action zone of the stress waves is large, usually 120 to 150 times the radius of the charge. ${ }^{6}$ Therefore, the kinetic effect of the backfill is mainly due to explosive stress waves. Under high-speed impact, the backfill is prone to damage, fracture, collapse and so on. Hence, it is necessary to study the response characteristics of the backfill in the condition of a dynamic load. In the second stage of the backstopping of backfill mining, parts of the stress waves are reflected on the contact surface between the backfill and rock layer, and another part invades into the backfill. At the very moment of blasting, the backfill is actually a superposition of the dynamic and static stresses. At present, research mainly focuses on laboratory experiments. The numerical simulation method has been widely used in rock and medium mechanics. But research on backfilling mechanics, especially on a mechanical characterization under dynamic load still needs to be improved.

From what is stated above, scholars at home and abroad have made fruitful research on backfilling mechanics, but are mainly based on the statics of fully filled samples, which cannot truly reflect the damage characteristics and mechanical response characteristics in the backfill mining process. Taking the deep stope of the Gaofeng mine in Guangxi Province (China) applying cemented backfilling method as the research object, this paper primarily focuses on the mechanical response law of mining induced stress under degradation of the parameters of the cemented backfill and mechanics under blasting coupling, which serves as a reference for the design of the field engineering.

\section{METHOD AND PRINCIPLE}

\subsection{The research basis}

The northern part of No. 105 Gaofeng mine of Huaxi Group is selected as the study area. So far, the mining method adopted in this area is mainly mechanized upward horizontal slicing cemented backfill, which causes less loss and dilution, but there are also some problems, such as bad working conditions, complex backstopping technologies, low production efficiency and high mining costs. Thus, the stability of the ore body should meet certain requirements; moreover, too many blasting times can easily lead to the accumulation of filling damage and the continuous expansion of cracks in the roof and pillar, so the exposed area and the span of stope should be strictly controlled. Otherwise, under the influence of the high-stress environment of the ore body itself and dynamic and static combined mechanical disturbance resulting from mining, roof caving and pillar instability can occur. Considering that Gaofeng Mine is a deep mine, the physical and mechanical properties of the ore body differ from those of the surrounding rocks under different geological conditions and environment. More detailed rock-mechanics data are needed to classify the rock mass quality, providing scientific grounds for mining safety.

According to the test types of the laboratory rock mechanics, the size and quantity of the rock samples are determined in accordance with the Standard of Engineering Rock Mass Test Method (GB/T 50266-2013). The rock blocks are processed, and then the uniaxial compressive strength, Brazilian test and triaxial compressive strength tests are carried out. Laboratory rockmechanics experiments were completed in the Mechanical Laboratory of the Center for Advanced Research (Center for Modern Analysis and Testing) of Central South University.

\subsection{Mechanical testing characteristics of the backfill}

In a deep well environment, the backfill is under high in-situ stress. With time, the confining pressure and the internal full hydrated reaction will change its mechanical parameters. In order to make the calculating parameters accurate, the actual quality and parameters of the backfill are evaluated. Tests are made using the laboratory preparation method and field backfilling core-taking method, respectively. The mechanical parameters of the rock and the backfill obtained are shown in Table $\mathbf{1}$.

\subsection{Analysis of the microscopic damage characteristics of the backfill}

The microscopic morphologies of the samples prepared in the laboratory and cored in-situ are obtained by SEM. In-situ coring is directly tested for stable samples.

Table 1: Mechanical parameters for calculation

\begin{tabular}{|c|c|c|c|c|c|c|c|}
\hline \multirow[b]{2}{*}{ Model partition } & \multicolumn{7}{|c|}{ Index } \\
\hline & $\begin{array}{l}\text { Bulk modulus } \\
\qquad(\mathrm{GPa})\end{array}$ & $\begin{array}{c}\text { Shear modulus } \\
(\mathrm{GPa})\end{array}$ & $\begin{array}{l}\text { Poisson's } \\
\text { ratio }\end{array}$ & $\begin{array}{l}\text { Cohesion } \\
(\mathrm{MPa})\end{array}$ & $\begin{array}{c}\text { Internal } \\
\text { friction angle } \\
\left({ }^{\circ}\right)\end{array}$ & $\begin{array}{l}\text { Uniaxial ten- } \\
\text { sile strength } \\
(\mathrm{MPa})\end{array}$ & $\begin{array}{l}\text { Bulk density } \\
\left(\mathrm{t} / \mathrm{m}^{3}\right)\end{array}$ \\
\hline Ore & 15.64 & 11.70 & 0.20 & 5.80 & 35.10 & 1.73 & 4.12 \\
\hline Wall rock & 24.18 & 15.21 & 0.24 & 3.52 & 28.90 & 1.05 & 2.70 \\
\hline backfill & 0.64 & 0.40 & 0.23 & 1.2 & 34.00 & 0.35 & 2.20 \\
\hline backfill core & 0.48 & 0.80 & 0.25 & 1.5 & 35.20 & 0.40 & 2.40 \\
\hline
\end{tabular}


Taken out on the $28^{\text {th }}$ day, the laboratory samples are soaked in absolute ethanol to stop the hydrated reaction. The micro-pore characteristics of the different backfill samples can be analyzed by testing.

Different substances have different micro morphologies. Tailings particles do not participate in the hydration reaction, still in the granular state. Cement hydration occurs, generating an amorphous $\mathrm{C}-\mathrm{S}-\mathrm{H}$ gel during the final stage. At the same time, there are still many pores in the three-dimensional grid gel, which is the location of the hydration reaction in the early stage, as well as the channel of water transport.

The pores in the solidified backfill will cause some damage to the strength, and the more pores there are, the more the intensity will be reduced.

When the tailings cemented backfill is subjected to compression, its deformation and damage process can be divided into four steps on the basis of the stress-strain curve obtained from the test. Gao and other researchers have studied the constitutive model under stress conditions, obtaining the damage evolution and constitutive equation of the backfill under compression: ${ }^{7}$
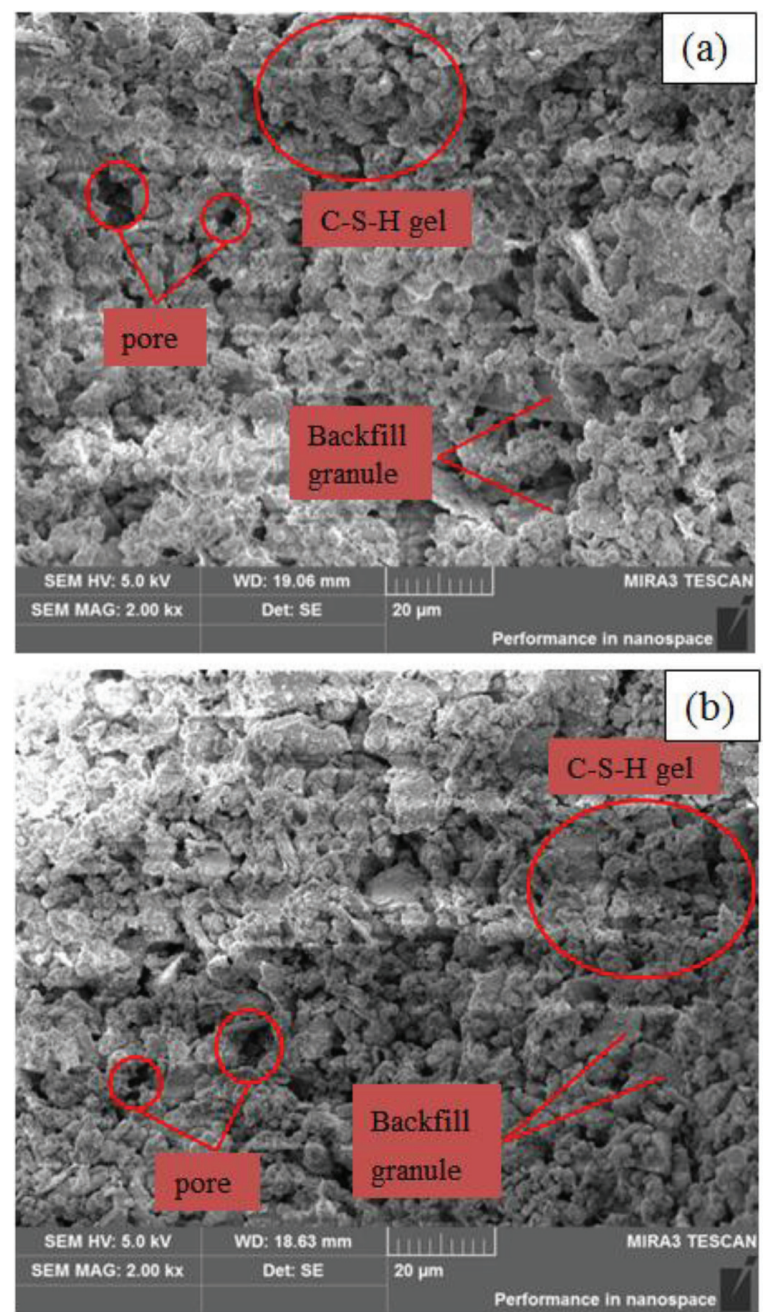

Figure 1: Microscopic topography of the backfill: a) in-situ coring, b) made in the laboratory

$$
\sigma=E \varepsilon\left\{\exp \left[-\frac{1}{m}\left(\frac{\varepsilon}{\varepsilon_{\mathrm{p}}}\right)^{\mathrm{m}}\right]\right\}
$$

In Equation (1), $\sigma$ is the compressive stress, $E$ is the elastic modulus, $\varepsilon$ is the strain, $\varepsilon_{\mathrm{p}}$ is the peak strain, and $m$ is the shape parameter of the Weibull distribution.

After the peak stress, $\varepsilon_{\mathrm{p}}<\varepsilon=\varepsilon_{\mathrm{u}}\left(\varepsilon_{\mathrm{u}}\right.$ is the limit strain value). The strength transition of the backfill before and after the peak reflected in the above model is too gentle, not in conformity with the definition of the ultimate strain. Based on the Mazars model, Liu et al. proposed that the post-peak damage $D$ as follows: ${ }^{8}$

$$
D=D_{\mathrm{p}}+1-\exp \left[-B\left(\varepsilon-\varepsilon_{\mathrm{p}}\right)\right]
$$

In the equation, $B$ is the damage parameters of the backfill, $D p$ is the damage value at peak stress:

$$
D_{\mathrm{p}}=1-\exp \left(-\frac{1}{m}\right)
$$

So, the damage constitutive equation of the backfill after the peak stress is as follows:

$$
\sigma=-E D_{\mathrm{p}} \varepsilon+E \varepsilon \exp \left[-B\left(\varepsilon-\varepsilon_{\mathrm{p}}\right)\right]
$$

\subsection{Inversion of the in-situ stress field}

The FLAC3D 5.0 finite-difference method is used to invert the stress environment of deep mining, verifying the rationality of the parameters and optimizing the structural parameters. According to Saint Venant's Principle, the influence area of the underground tunnel is 3-5 times its excavation area. To ensure the accuracy of the simulation excavation, the relevant parameters of the model are determined as: $1160 \mathrm{~m}$ long, $1130 \mathrm{~m}$ wide and $504 \mathrm{~m}$ high (with 856278 elements).

By means of the numerical simulation software Madis GTS NX, the geometric model and the mesh generation are completed. Then the conversion interface program Midas GTS NX to FLAC 3D 5.0_64bit is employed to convert the data and, finally, the converted mesh model is imported into FLAC 3D. The ore body mesh model is shown in Figure 2.

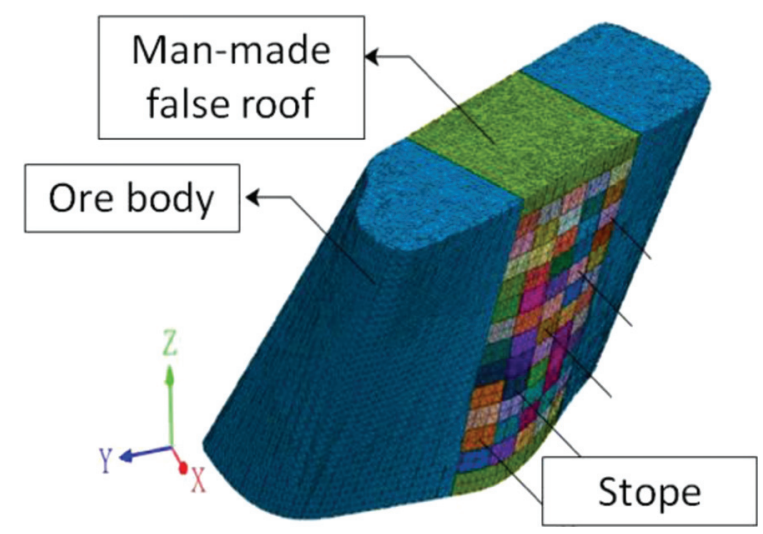

Figure 2: Computational domain grid model 


\subsection{Analysis of the mechanical response law of the backfill under a dynamic and static combined dis- turbance}

According to the characteristics of the upward horizontal slicing and backfilling method in the Gaofeng mine, the whole backstopping mining procedure has been taken into consideration in the numerical simulation process. The results of the stress-field evolution calculated by the original rock stress inversion are used as the initial stress environment to assign the values. The calculation process is divided into four types of working conditions for the dynamic and static combined mechanics calculation, as shown in Figure 3.

1) Working condition 1: simulation of the effects of a combined dynamic and static disturbance in the first stage of backstopping of the first two layers. The rock mass at the bottom of the model is excavated, and then explosives are buried in the upper layer to observe the stress-strain state of the roof and the pillars on both sides of the excavation area after blasting.

2) Working condition 2: simulation of the effects of dynamic and static combined disturbance in the first stage of backstopping of the last layer. The uppermost layer of the rock mass in the model is excavated, and then explosives are buried in the last layer to observe the stress-strain state of the man-made false roof and pillars on both sides of the excavation area after blasting.

3) Working condition 3: simulation of the effects of dynamic and static combined disturbance in the second stage of backstopping of the first two layers. The rock mass at the bottom of the model is excavated, and then explosives are buried in the upper layer to observe the stress-strain state of the roof and backfill on both sides of the excavation area after blasting.

4) Working condition 4: simulation of the effects of a dynamic and static combined disturbance in the second stage of backstopping during the mining of the last layer. The uppermost layer of the rock mass in the model is excavated, and then explosives are buried in the last layer to observe the stress-strain state of the man-made false

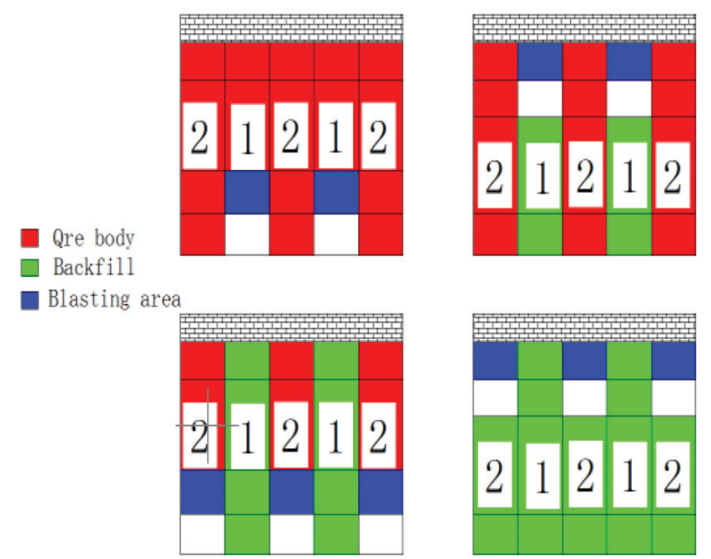

Figure 3: Blasting schemes setting diagrams under different working conditions roof and backfill on both sides of the excavation area after blasting.

The simulation is based on the mechanical parameters of the ore and rock near the testing stope in the north of Gaofeng mine. The model selected is identical with the initial one. The materials and parameters are also in conformity with those of the initial one. The meshing method, algorithm and calculation termination time are the same. The magnitude and application method of the initial in-situ stress are the same as those of the previous two parts. The constrained conditions are also consistent, both applied directly to the model in ANSYS static analysis and invoked in the LS-DYNA dynamic analysis using a drelax file. For the convenience of the simulation calculation, the calculation method of the excavation before blasting is adopted. The charge of a single hole is $3.3 \mathrm{~kg}$, equivalent to $1.92 \mathrm{~kg}$ of TNT. The major purpose of the blasting simulation calculation is to observe and study the propagation law for blasting stress waves in a rock mass, and to simulate the conclusion of the numerical calculation in the previous section, so as to find out the implicit-explicit solution by using the advantages of ANSYS and ANSYS/LS-DYNA in static and dynamic analysis, respectively.

\section{RESULTS AND DISCUSSION}

\subsection{Microstructure and constitutive characteristics of the backfill}

According to the analysis of Figure 1, the C-S-H gel of the field sample is evidently more evenly distributed, and the three-dimensional network structure is more closely linked. The C-S-H gel in vision has been integrated into the one with the tailings particles wrapped in it. Whereas, in the sample taken from the laboratory, the distribution of the C-S-H gel is rather uneven, and there are many exposed tailings particles. The gel dispersed around the tailings particles, forms no three-dimensional mesh structures. The overall structure is loose, and there are more pores between the particles. Extracting the area and the number of white pixels in the binary image, the statistical results are as shown in Figure 4.

It can be seen from the figure that the pore area of the field and laboratory sample is concentrated between 0.2 and 0.3 , but the proportion of the former reaches $28 \%$, while that of the latter is $23 \%$. There are almost no macro pores in the field sample, but many in the laboratory one, which indicates that there are more pores in the field backfill, the size of which is smaller, while in the sample made in the laboratory, the pores are fewer and larger. Meanwhile, the plane voids and total voids of the field sample are lower than those of the laboratory one.

Comparing the increase of the elastic modulus, it shows that the structure of the field backfill is more compact under the influence of the confining pressure and 

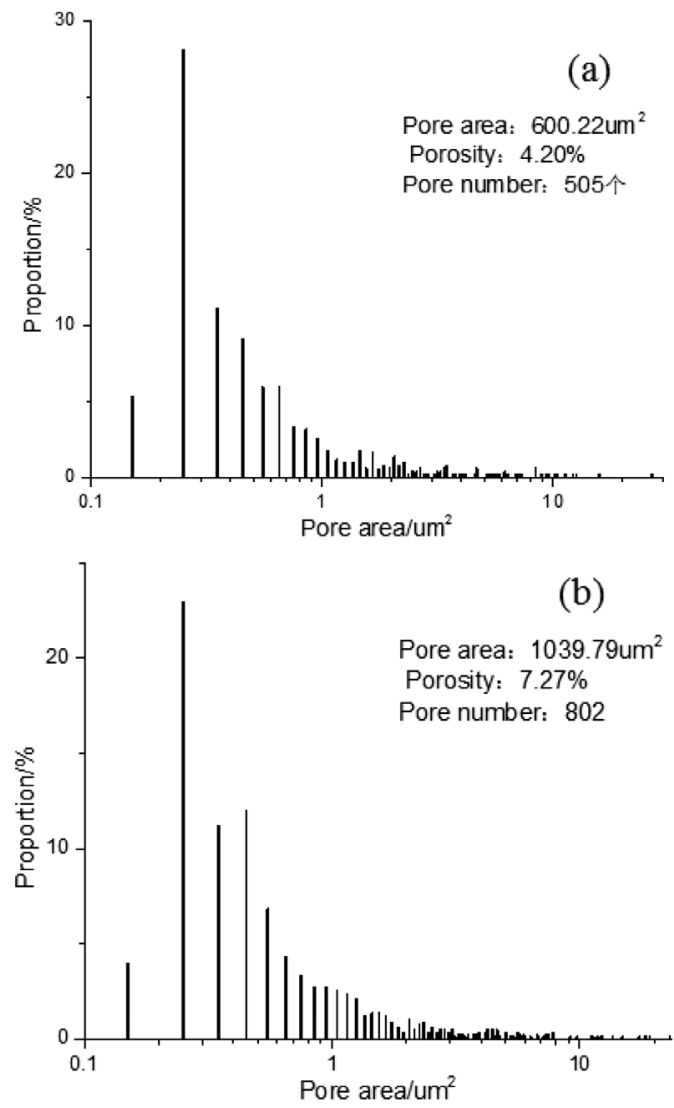

Figure 4: Statistics of the pore area proportion of the backfill: a) in-situ coring, b) made in the laboratory

the continuous hydration reaction, and thus its quality is better than that made in the laboratory. According to the test results, the damage parameters of the different types of backfill are calculated using formulas (1), (2) and (3), as presented in Table 2.

\subsection{Verification of static field inversion in deep mining}

In order to reduce the influence of the backfill damage in the study area, the constitutive relation is analyzed based on the mechanical characteristics of the backfill damage, which are then adjusted. The elastic modulus $E$ of the backfill is revised with the strain rate as the reference variable to dynamically update the calculation model. Thereby, the synchronous adjustment of the FLAC 3D bulk modulus $K$ and the shear modulus $G$ is achieved.

Different from the dynamic simulation method, which usually adopts a uniform stress field, this paper employs ANSYS to introduce the excavation process and the inversion of stress environment simulated by FLAC 3D into LS-DYNA software to analyze the blasting dynamics after the excavation. In the last century, it was generally believed that the maximum shear stress yield criterion proposed by Tresca in 1864 was correct. The idea proposed by Mises in 1913 is similar to the Tresca yield criterion. ${ }^{9}$ Unlike the Tresca criterion, we need to know which stress is the largest and which is the smallest. Lode has carried out yield criterion tests, proving that the Mises criterion is closer to the experimental result of the materials. This is a classic experiment and has been cited in many books. It should be noted that Lode first analyzed the substantive difference between the two yield criteria, pointing out that the main difference between them is whether to consider the influence of the intermediate principal stress. The Tresca criterion does not take it into consideration. Its formula is as follows:

$$
\sigma_{1}-\sigma_{3}=Y
$$

In the formula, $\sigma_{1}$ and $\sigma_{3}$ are the maximum and minimum principal stress, respectively, and $Y$ is the dynamic stress of the materials.

Mises has revised the Tresca criterion, taking the influence of the intermediate principal stress into account. The new formula is:

$$
\left(\sigma_{1}-\sigma_{2}\right)^{2}+\left(\sigma_{2}-\sigma_{3}\right)^{2}+\left(\sigma_{3}-\sigma_{1}\right)^{2}=2 Y^{2}
$$

In the formula, $\sigma_{2}$ is the intermediate principal stress.

The Lode number is introduced as the influence parameter of the intermediate principal stress when allocating reasonable parameters, and thus the formula is as follows:

$$
\mu_{\sigma}=\frac{\sigma_{2}-\left(\sigma_{1}+\sigma_{3}\right) / 2}{\left(\sigma_{1}-\sigma_{3}\right) / 2}
$$

The strain type is determined by $\mu_{\sigma}$. When $\mu_{\sigma}>0$, a compressive strain occurs; when $\mu_{\sigma}<0$, then an elongation strain and when $\mu_{\sigma}=0$, plane strain. $\mu_{\sigma}$ also determines the ratio of the strain increment.

As shown in Figure 5, the initial stress environment is inverted by ANSYS. After excavating partly, the stress in the stope redistributes. The known first-principal stress, intermediate principal stress and third-principal stress of the study area are inverted, taking the Lode number acquired from calculating all the elements in the traversal model by formula (6), as the evaluation criterion. From the figure it can be concluded that most of the

\begin{tabular}{|c|c|c|c|c|c|c|c|}
\hline \multirow[t]{2}{*}{ Types of backfill } & $\begin{array}{c}\text { Elastic modulus } \\
\mathrm{E} / \mathrm{MPa}\end{array}$ & $\begin{array}{c}\text { Peak stress } \\
\sigma_{\mathrm{p}} / \mathrm{MPa}\end{array}$ & $\begin{array}{c}\text { Peak strain } \\
\varepsilon_{\mathrm{p}}\end{array}$ & $\begin{array}{c}\text { Peak damage } \\
D_{\mathrm{p}}\end{array}$ & \multicolumn{3}{|c|}{ Damage parameter } \\
\hline & & & & & $\mathrm{m}$ & $1 / \mathrm{m}$ & B \\
\hline Made-in the lab & 993 & 2.0 & 0.0118 & 0.83 & 0.566 & 1.768 & 16.71 \\
\hline Field coring & 1203 & 3.02 & 0.012 & 0.79 & 0.641 & 1.560 & 18.14 \\
\hline
\end{tabular}
stope is in the compressive strain environment, and the

Table 2: Table of the constitutive parameters of the backfill 


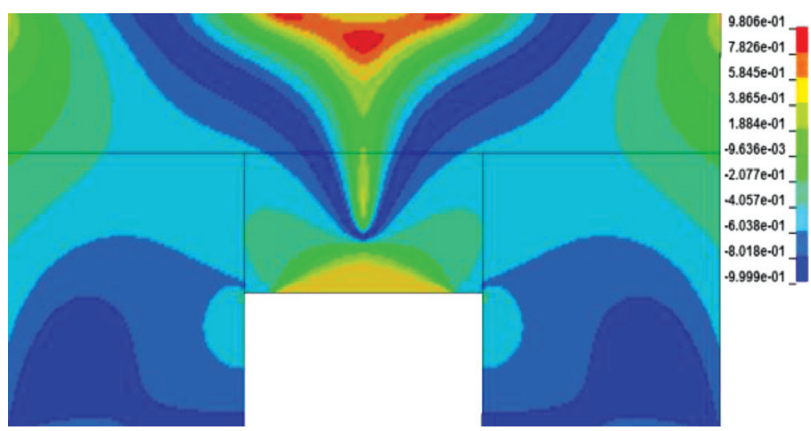

Figure 5: Distribution diagram of the Lode parameters in the initial state

maximum strain is concentrated in the center of the roof. Due to the stress release effect caused by the excavation, a certain range of tensile strain is formed on both sides of the pillars. This state explains that the initial stress is effective and the stress-strain environment in the stope before blasting is better restored.

The simulation is conducted in the way of first excavating the lower layer of the blasting area and then blasting in the rock mass to observe the stress-strain state of the roof in the middle layer and the pillars on both sides under the influence of the excavation and the dynamic and static forces of the blasting. Through the calculation, the propagation of the vibration velocity and the effective stress nephogram of Von Mises in the excavated rock mass during the blasting process are obtained. The propagation of the explosive stress waves in this area is to be recognized.

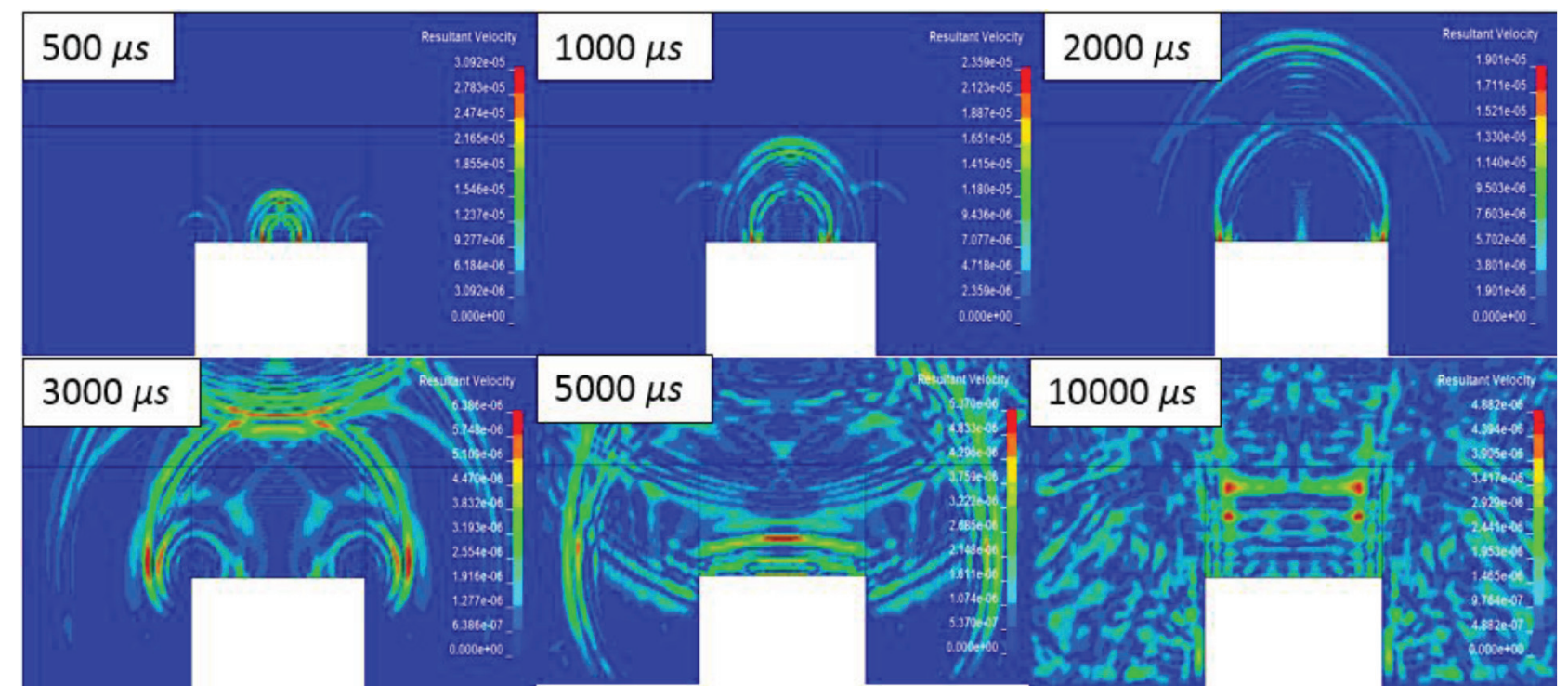

Figure 6: Distribution of the vibration velocity at different times

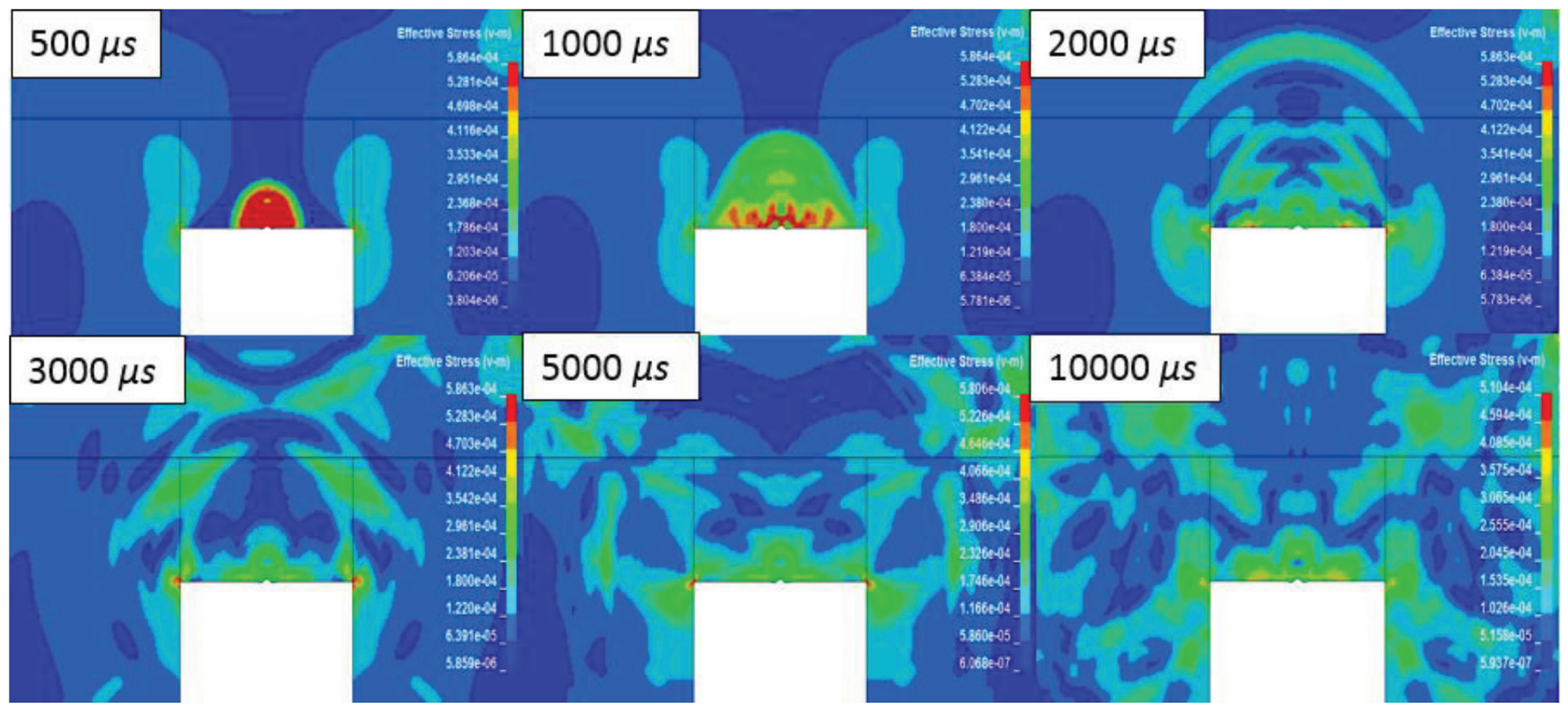

Figure 7: Distribution of the effective stress at different times 
Through analyzing the corresponding vibration velocity and stress nephogram when the variable $t$ is assigned as $500 \mu \mathrm{s}, 1000 \mu \mathrm{s}, 2000 \mu \mathrm{s}, 3000 \mu \mathrm{s}, 5000 \mu \mathrm{s}$ and $10000 \mu \mathrm{s}$, respectively, the diffusion law and the velocity distribution of the stress waves in the rock mass after the explosion can be observed, especially the stress change in the vicinity when the explosive stress waves propagate to the roof and pillar.

\subsection{Simulation of the dynamic disturbance influence of the backfill under mining-induced stress}

According to the figures, this simulation defines the initial parameters of the backfill by the damage characteristics, without considering the structural planes in the rock mass, coupling the mining-induced stress and blasting dynamics. The stress variation laws of the roof and the pillar in the excavation area are as follows:

1) Before blasting, the roof position is only affected by the high geostress and the mining-induced stress. The roof stress is lower than the initial in-situ stress and the stress of the surrounding rocks on both sides. There is a certain range of stress concentration in the excavation area. After blasting, the stress waves first diffuse uniformly in all directions, with no obvious change in the roof stress in the excavation area and rock mass stress in other blasting areas.

2) With the propagation of vibration, the energy of the stress waves propagates towards the excavation area, leading to the phenomenon that the stress is concentrated in this area and is stronger than that in other surrounding areas. It can be concluded that the excavation area has an inductive effect on the propagation of explosive stress waves, inducing more explosive energy to propagate to it.

3) When the stress waves propagate through the roof, they pass the free surface, with the reflection of which, reflected waves are generated and propagate to the direction of the explosion source. The initial energy of the waves is very strong, and the roof bears a very powerful reflection stress. When the reflected waves pass by, the interface is still in stress, the value of which is greater than that of the other areas.

4) When the stress waves pass through the pillars on both sides of the excavation area, a certain range of stress concentration occurs. As time goes by, the vibration velocity decreases step by step, although the vibration effect occurs in each area. The peak area of the vibration velocity appears in the blasting area most of the time.

In deep mining of Gaofeng mine, the effects of coupled mining-induced stress and blasting dynamics on the roof of the excavation area are studied. By analyzing the effective stress nephogram, the conclusion can be reached that owing to the fact that the roof stress of the excavation area is affected by the mining-induced stress before blasting, the roof stress of the excavation area transfers to the pillars on both sides; the mining induced stress then induces the explosive energy to propagate towards the excavation area after blasting, thus the roof stress is greater than that of the surrounding rocks. In addition, it can be seen that the effects of the stress-wave reflection at the interface are rather obvious and cannot be ignored.

\subsection{Analysis of the effects of a dynamic and static com- bined disturbance}

In order to clearly analyze the stress change of the excavation area during the blasting process, units are
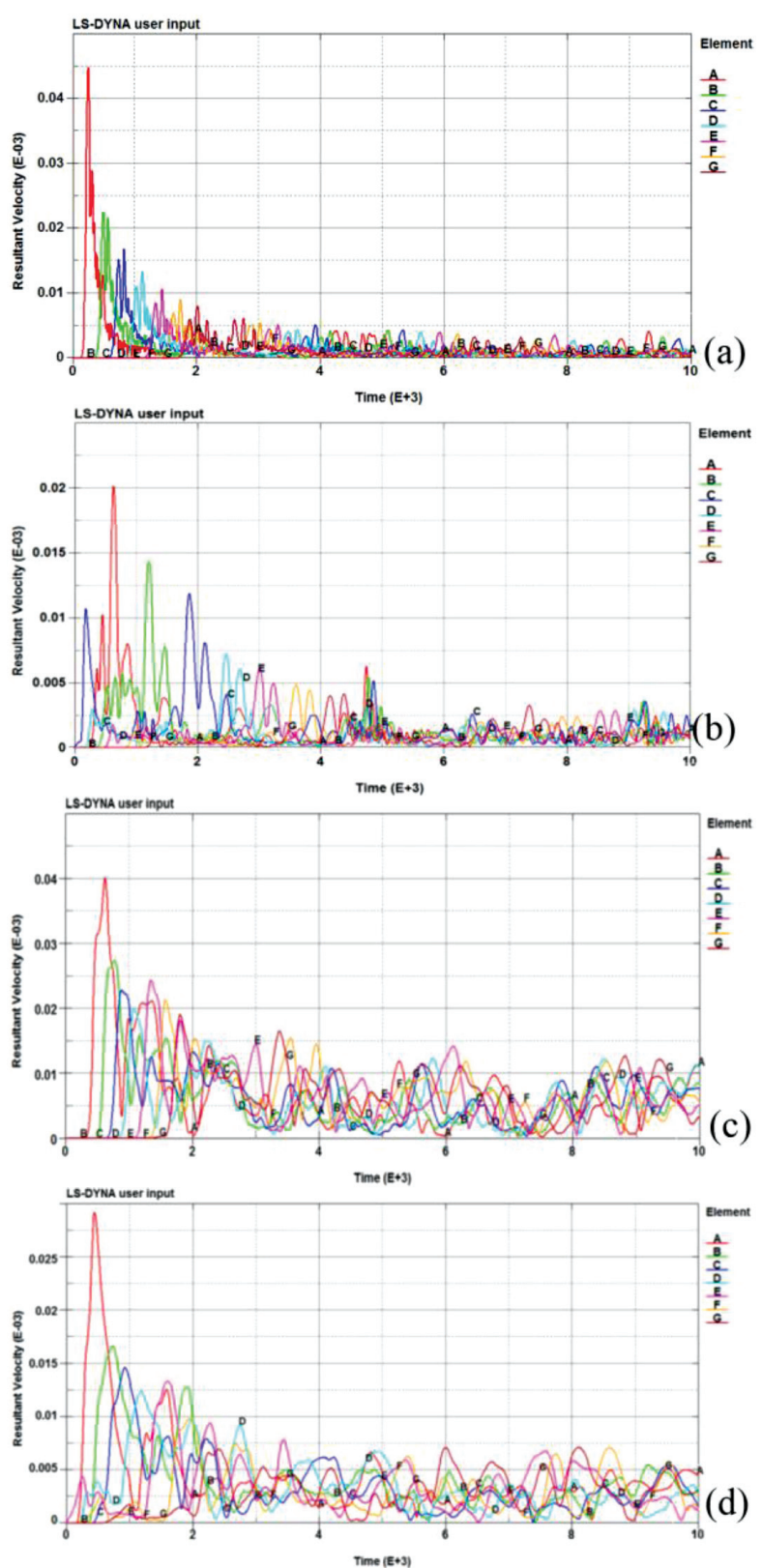

Figure 8: Variation of the horizontal vibration velocity of different units along with time a) vertical vibration velocity in working condition $1, \mathrm{~b}$ ) horizontal vibration velocity in working condition $1, \mathrm{c}$ ) vertical vibration velocity in working condition 4 , d) horizontal vibration velocity in working condition 4 . 
selected from the vertical and horizontal directions of the self-explosion source center at distances of $2 \mathrm{~m}, 3 \mathrm{~m}$, $4 \mathrm{~m}, 5 \mathrm{~m}, 6 \mathrm{~m}, 7 \mathrm{~m}$ and $8 \mathrm{~m}$, respectively, to observe the changes in the stress wave movement and vibration velocity.

Due to the large quantity of data to be monitored, the comparative analysis of the stress-wave propagation characteristics under backfilling and non-backfilling circumstances is carried out by only selecting the monitoring curves of working conditions 1 and 4 .

As shown in Figure 8, the seven curves represent the variation of the vibration velocity of the seven units $A-G$ during the blasting process. The units of speed and time are software default units, which are in $\mathrm{cm} / \mu$ s and $\mu \mathrm{s}$ respectively. By analyzing the simulation results, it can be concluded that the basic laws of the effective stress and vibration velocity of the rock mass are similar, i.e., the closer it is to the unit of the explosive model, the earlier the maximum stress and vibration velocity peak appear, falling back after reaching the peak, and eventually fluctuating around a relatively stable value. Units A-D are in the blasting area and E-G are inside the pillar. Comparing working conditions 1 and 4 , it can be found that in the mining environment with backfill, the distribution of vibration velocity in working condition 1 differs from that in working condition 4 due to the difference of the stress-wave propagation in different media and the transition at the interface:

1) It can be seen from the vibration velocity curve of working condition 1 that when the explosive is detonated, the blasting energy attenuates sharply in the near zone, and slowly decays in the middle and far zone; the vibration velocity in the vertical direction exceeds that in the horizontal direction, hence the response time of the peak vibration velocity is also shorter, indicating that the stress waves in the vertical direction are stronger. When the stress waves propagate from the blasting area to the pillar, the vibration velocity attenuation before and after is quite regular due to the same type of medium.

2) In working condition 4, the vibration velocity attenuation in the blasting area is the same as that in working condition 1 , but as the stress waves cross the boundary between the rock mass and backfill, the vibration velocity rebounds slightly. It is because the stress release produces elastic deformation energy, and the backfill is more sensitive as a propagation medium that the vibration velocity rebounds in the full-filled environment. Furthermore, after the stress waves enter the backfill, the attenuation amplitude is significantly smaller than before, and the propagation and response are much quicker.

From the design form and results of the vibration velocity monitoring, stress waves basically propagate in the vertical direction and have less influence in the horizontal direction as a result of the lower unloading space. In order to more intuitively observe the above characteristics, proving the excavation area is affected by the explosion stress waves in the high-stress rock mass, the data of the maximum stress and vibration velocity peak in the vertical direction of each scheme are recorded, as shown in Table 3.

Under the influence of excavation, the unloading effect appears below the blasting area, so the peak stress and peak vibration velocity are substantially lower in the horizontal direction than those in the vertical direction. The closer it is to the excavation area, the greater the distinction is; comparing the other data, the following phenomena can also be revealed:

1) The peak stress of unit $A$ is always $58.63 \mathrm{MPa}$ in each working condition. It can be seen from the nephogram that at the very moment when initial detonation waves come into being, the stress near the core area reaches the peak, to which unit A is close, thus is covered by it.

2) The vibration velocity and stress peak in each unit attenuate as the increase of the detonation distance, and the initial attenuation is greater and then decreases. Working condition 3 and 4 are backstopping in the second period of mining, and the final vibration velocity peaks are higher than those in the other two working conditions. Moreover, in working condition 4, the vibration velocity rebounds in unit $\mathrm{E}$, and the attenuation amplitude is sharply reduced. The blasting area is full-filled in working condition 4, indicating that the stress-wave propagation in the backfilling environment is different from that in the rock mass.

In order to further analyze the propagation characteristics of the stress waves in the media of the rock mass and backfill, Rubio et al. proposed that concrete and brittle rock materials have typical viscoelastic charac-

Table 3: Blasting vibration stress and peak vibration velocity under different working conditions

\begin{tabular}{|c|c|c|c|c|c|c|c|c|}
\hline Unit no. & $\mathrm{A}$ & $\mathrm{B}$ & $\mathrm{C}$ & $\mathrm{D}$ & $\mathrm{E}$ & $\mathrm{F}$ & \multicolumn{2}{|c|}{$\mathrm{G}$} \\
\hline \multirow{2}{*}{$\begin{array}{l}\text { Working } \\
\text { condition } 1\end{array}$} & Peak stress & 58.63 & 34.53 & 26.97 & 17.31 & 13.76 & 12.00 & 10.55 \\
\hline & Peak vibration velocity & 44.41 & 22.37 & 16.77 & 13.11 & 10.42 & 9.09 & 7.99 \\
\hline \multirow{2}{*}{$\begin{array}{l}\text { Working } \\
\text { condition } 2\end{array}$} & Peak stress & 58.63 & 31.63 & 21.44 & 16.61 & 13.60 & 12.52 & 12.19 \\
\hline & Peak vibration velocity & 46.21 & 23.97 & 15.08 & 14.83 & 12.40 & 10.26 & 9.62 \\
\hline \multirow{2}{*}{$\begin{array}{c}\text { Working } \\
\text { condition } 3\end{array}$} & Peak stress & 58.63 & 37.02 & 22.82 & 17.64 & 14.11 & 12.83 & 12.69 \\
\hline & Peak vibration velocity & 43.02 & 28.38 & 23.63 & 17.38 & 15.37 & 13.79 & 11.53 \\
\hline \multirow{2}{*}{$\begin{array}{l}\text { Working } \\
\text { condition } 4\end{array}$} & Peak stress & 58.63 & 36.12 & 24.94 & 21.12 & 15.00 & 13.65 & 12.75 \\
\hline & Peak vibration velocity & 39.91 & 27.49 & 22.89 & 20.04 & 24.10 & 21.01 & 19.26 \\
\hline
\end{tabular}


teristics, and the pure exponential decay law of stresswave propagation is obtained: ${ }^{10}$

$$
\sigma_{\mathrm{p}}=\sigma_{0} e^{-\alpha l}
$$

In the formula, $\alpha$ is the attenuation coefficient related to the material parameters and the intensity of the stress waves. The smaller the value is, the greater the attenuation amplitude becomes; $\sigma_{0}$ is the initial peak stress; $l$ is the detonation distance between the blasting center and the response point.

However, according to formula (7), the attenuation speed of the stress waves is too fast, which is inconsistent with the shallow hole arrangement and blasting response characteristics near the backfill. Zhu et al. have considered the case of a longer stress-wave propagation time and proposed a modified attenuation equation: ${ }^{11}$

$$
\sigma_{\mathrm{p}}=\sigma_{1}+\sigma_{2} e^{-\alpha l}
$$

In the equation, $\sigma_{1}$ and $\sigma_{2}$ are the attenuation parameters, which characterize the non-attenuated elastic wave component and the exponentially decaying viscoplastic wave component.

For the purpose of reasonably describing the corresponding characteristics of the stress-wave propagation, the data of working conditions 1 and 4 are selected as the fitting basis for the attenuation-detonation distance of the stress peak and the vibration velocity peak. Due to the influence of the unloading effect in the static excavation state, the vertical direction propagation data are selected for analyses. From the position of the interface of the medium, it can be inferred that the critical point of the transformation is between unit D and E. In order to make the analysis more accurate, the data after unit $\mathrm{E}$ are selected to analyze the backfilling medium, and more units are chosen to further refine the data changes.

Since the stress-wave propagation in the rock mass is integrate, data from unit $A-G$ are directly selected for analyzing. The fitting curve of the relationship of attenuation and detonation distance of these units is shown in Figure 9.

Figure 9a is the attenuation curve of the peak stress with a fitting degree of $99.10 \%$; Figure $9 \mathbf{b}$ is the attenuation curve of the peak vibration velocity with a fitting degree of $98.75 \%$. The curves show that the attenuation of the peak stress and the peak vibration velocity of each unit is in accord with the exponential law, i.e., when the distance of the mass point from the free face of blasting area is shorter than a certain value (about $3 \mathrm{~m}$ here), the peak and velocity of the stress waves sharply attenuate. As the distance continues to expand, the attenuation tends to be stable. The fitting formula is as follows.

Equation of the peak stress attenuation in the rock mass:

$$
\sigma_{\mathrm{p}}=9.26+87.43 e^{-l / 1.72}
$$

Equation of the peak vibration velocity attenuation in the rock mass:

$$
V_{\mathrm{p}}=8.91+80.85 e^{-l / 1.20}
$$

According to the previous analysis, the variation of the peak vibration velocity and the stress in the rock mass is similar to that in the above curve. The change of the vibration velocity can reflect the fluctuation of the stress value, which is also the basis of the engineering blasting vibration test. Blasting generates blasting vibration velocity and induced stress in the rock mass. Then, according to the superposition characteristics of the blast wave in the propagation, the vibration velocity and stress of the particle after blasting will form an immediate correlation. The vibration speeds of the adjacent segments are close to each other and superimposed with the increase of the propagation distance, so that the surrounding rock mass produces a stress response state corresponding to the interference. In the light of the fitting formula, the peak stress and vibration velocity of the high-stress blasting rock attenuates exponentially with the detonation distance, and the decrease of the former is faster.

It is reflected in working condition 4 that when the stress waves propagate from the rock mass to the backfill, its peak value and attenuation begin to change,
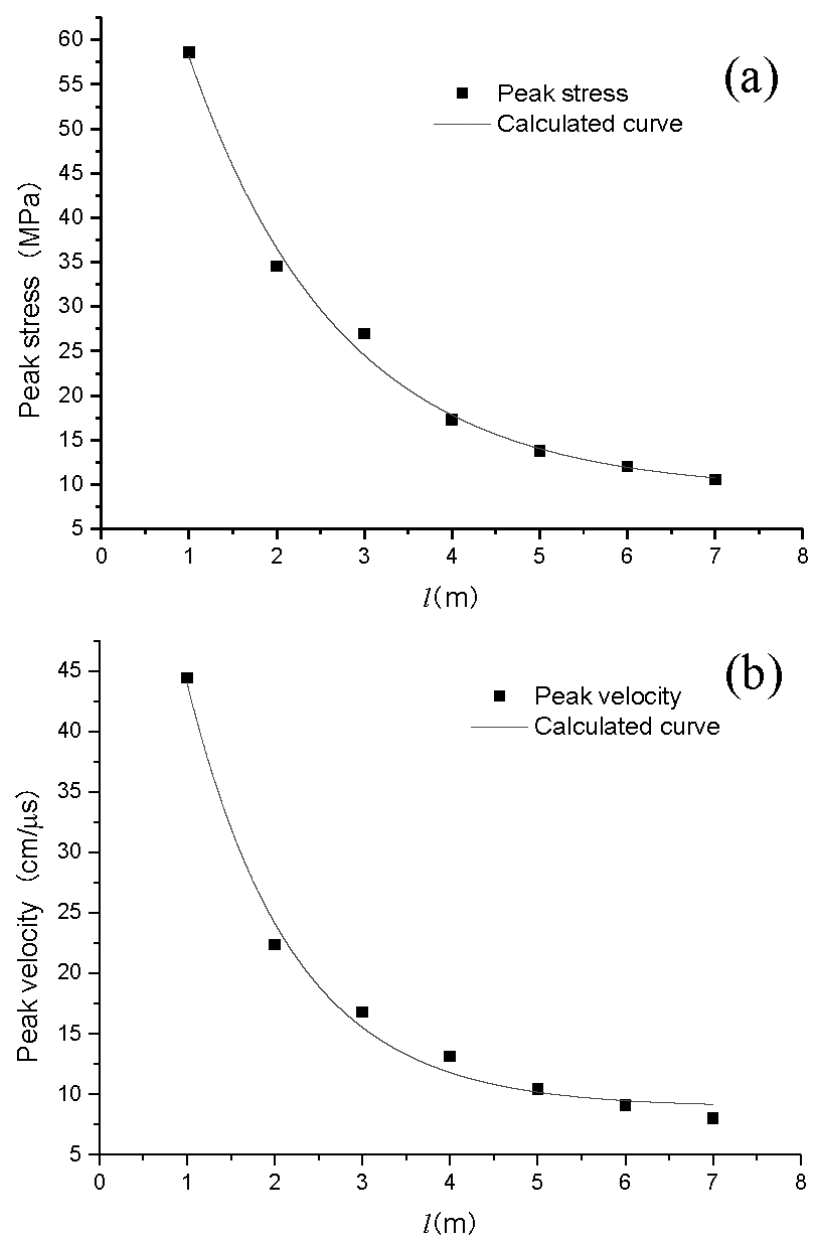

Figure 9: Fitting curve of the response parameters of the rock mass and the detonation distance:a) stress peak, b) vibration velocity peak 

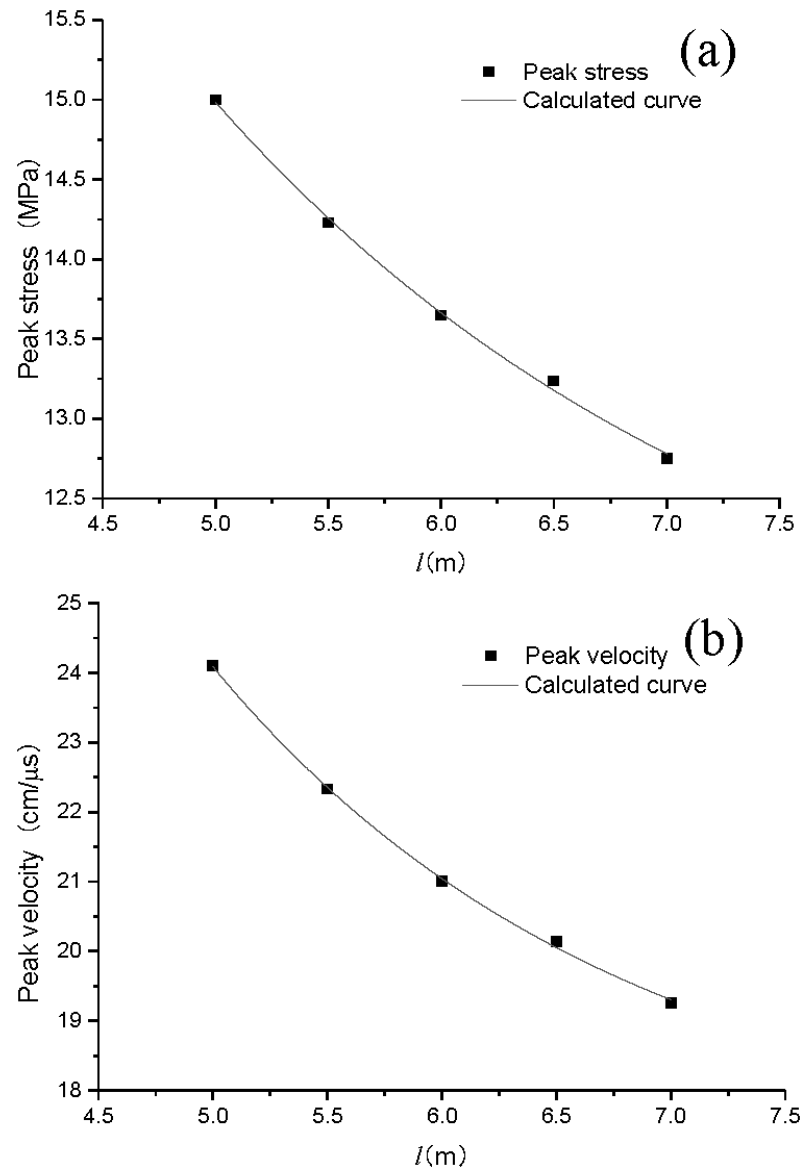

Figure 10: Fitting curve of the response parameters of the backfill and detonation distance: a) peak stress, b) peak vibration velocity

i.e., the attenuation amplitude decreases or even the peak value rebounds. As regards the analysis of the stresswave propagation in the backfill, since blasting does not directly occur in the backfill, this paper applies the upward horizontal stratified backfilling method applied in the actual project of the Gaofeng mine to analyze the stress wave data of the full-filled environment around the blasting area in working condition 4. Data taken from unit E-G with an interval of $0.5 \mathrm{~m}$ are refined, obtaining the fitting curve of the relationship of attenuation and detonation distance of these units as shown in Figure 10.

Figure 10a is the attenuation curve of the peak stress with a fitting degree of $99.64 \%$; Figure 10b is the attenuation curve of the peak vibration velocity with a fitting degree of $99.84 \%$. Though the peak stress and the vibration velocity of each unit is still in line with the exponential distribution law of the equation, it is actually close to the linear attenuation state, and the attenuation speed is apparently slower than that of the exponential in the rock mass. The fitting formula is as follows.

Equation of the peak stress attenuation in the backfill:

$$
\sigma_{\mathrm{p}}=11.00+29.87 e^{-l / 2.48}
$$

The equation of the peak vibration velocity attenuation in the backfill:

$$
V_{\mathrm{p}}=16.98+116.56 e^{-l / 1.79}
$$

On the grounds of the previous analysis, a variation of the peak vibration velocity and the stress of the blasting stress waves propagating in the backfill is basically similar to that in the above curve in Figure $\mathbf{1 0}$. Through the analysis of the data of working conditions 2 and 4 , it can be concluded that when the stress waves cross the interface of the medium to enter the backfill, the decay of the vibration velocity is getting slower and even rebounds. It can also be seen from the fitting formula and the curve that the stress waves respond more frequently in the backfill and the attenuation amplitude becomes smaller, indicating that the blasting vibration has a larger influence range in the backfill, to which attention should be paid in engineering.

Comparing Table 3 with the results of the horizontal vibration velocity monitoring, it is found that in the rock mass environment, all blasting vibration can attenuate rapidly, restricting the effects to a small range, and the maximum value does not exceed $15.0 \mathrm{~cm} / \mathrm{s}$. The response of the backfill to dynamic disturbance is more sensitive. In working conditions 2 and 4, both roofs are backfilled, and the maximum vibration velocity reaches $12.4 \mathrm{~cm} / \mathrm{s}$ and $24.1 \mathrm{~cm} / \mathrm{s}$, respectively, both exceed the safety standard, which is $11.0 \mathrm{~cm} / \mathrm{s}$. Because of the unloading influence underneath, the impact of the blasting vibration on the pillars on both sides is small. Only the near-end (unit E) in working condition 4 exceeds the standard, but the scope of the influence is not large. Therefore, when the first stage of backstopping is near to the roof of the backfill (working condition 2), the amount of explosive should be properly controlled to reduce the vibration impact. As to the backstopping of the uppermost layer in the second period of mining (working condition 4), except from reducing explosive, the blasting zone should also be minimized, and the stope should be closed in time to prevent instability and collapse of the backfill pillar. From the analysis of the mechanical response characteristics, the quality of the current backfill of Gaofeng mine can meet the safety requirements of most mining blasting, but corresponding construction scheme and safety measures should be given for direct blasting under the roof of backfill.

\section{CONCLUSIONS}

This study looks at the mechanical characteristics of backfilling and the disturbance response law in a deep mining environment. Combined with the theory of damage mechanics and the numerical inversion method, the stress environment of backfilled deep mining is restored, and the mechanical response law of backfilled mining under dynamic and static combined disturbance is analyzed by the aid of stress wave propagation theory. The principal conclusions are as follows:

(1) Combined with the SEM binarization analysis results, it was found that the plane void ratio and the 
total number of pores of the field sample are both smaller than those of the laboratory sample. With the increase of elastic modulus taken into consideration, it implies that the structure of the field backfill is more compact under the influence of the confining pressure and continuing hydration reaction, and hence the quality is also better.

(2) The cumulative evolution of the internal damage leads to a macroscopic fracture of the backfill, and the study of the damage evolution constitutive relationship can contribute to the analysis of the deformation performance of the backfill. Based on the Lemaitre strain equivalence principle and Weibull distribution theory of material micro-division, the stress-strain damage constitutive model of the backfill is established, laying a foundation for the numerical inversion of the deep stress environment.

(3) In order to realize the coupling of the dynamic and static disturbance, the backfill damage constitutive model is introduced into the research of area model by dynamically updating the elastic modulus in FLAC3D 5.0 , so as to realize the synchronous adjustment of the volume modulus $\mathrm{K}$ and the shear modulus $\mathrm{G}$. The Lode parameters obtained from the calculation under the Mises criterion verifies that the inversion results are valid.

(4) ANSYS/LS-DYNA was used to analyze the mechanical response law of the mining-induced stress under high stress and backfill mining under blasting coupling, and the attenuation curve and the formula of the peak stress and vibration velocity with detonation distance are formed. It is analyzed that the decrease of the blasting peak stress and the vibration velocity is in accordance with the exponential law. When the stress waves cross the interface of the medium and enter the backfill, it responds more frequently with the attenuation amplitude significantly reduced, and the impact zone of the blasting vibration expanded. The combination of the static analysis and the dynamic response more realistically reflects the mechanical response characteristics of deep mining, which is more accurate than conventional dynamic analysis methods.

\section{Acknowledgments}

This work was financially supported by the National Natural Science Foundation of China (grant no. 51774323).

\section{REFERENCES}

${ }^{1}$ L. Liu, Z. Fang, C. Qi, B. Zhang, Experimental investigation on the relationship between pore characteristics and unconfined compressive strength of cemented paste backfill, Powder. Technol., 179 (2018), 254-264, doi:10.1016/j.conbuildmat.2018.05.224

${ }^{2}$ J. H. Hu, Q. F. Ren, Q. Jiang, Strength characteristics and the reaction mechanism of stone powder cement tailings backfill, Adv Mater Sci Eng., (2018), doi:10.1155/2018/8651239

${ }^{3}$ L. Orejarena, M. Fall, The use of artificial neural networks to predict the effect of sulphate attack on the strength of cemented paste backfill, B. Eng. Geol. Environ., 69 (2011) 4, 659-670, doi:10.1007/ s10064-010-0326-7

${ }^{4}$ K. P. Zhou, R. G. Gao, F. Gao, Particle flow characteristics and transportation optimization of superfine unclassified backfilling, Miner., 7 (2017) 6, doi:10.3390/min7010006

${ }^{5}$ E. Bayram, K. Ayhan, C. Ferdi, Cemented paste backfill of sulphide-rich tailings: Importance of binder type and dosage, Cement. Concrete. Comp., 31 (2009) 4, 268-274, doi:10.1016/j.cemconcomp. 2009.01.008

${ }^{6}$ F. H. Zhou, M. JF, On the rate-dependency of dynamic tensile strength of a model ceramic system, Comput. Method. Appl. M., 194 (2005) 12, 1693-1709, doi:10.1016/j.cma.2003.12.076

${ }^{7}$ R. G. Gao, K. P. Zhou, J. L. Li, Research of the mechanics of backfill formation and damage, Mater. Tehnol., 52 (2018) 2, 163-169, doi:10.17222/mit.2017.070

${ }^{8}$ Z. X. Liu, M. Lan, S. Y. Xiao, Damage failure of cemented backfill and its reasonable match with rock mass, T. Nonferr. Metal. Soc., 25 (2015) 3, 954-959, doi:10.1016/S1003-6326(15)63684-6

${ }^{9}$ A. Nelli, Application of Mises yield criterion to rotating solid disk problem, Int. J. Eng. Sci., 51 (2012), 333-337, doi:10.1016/ j.ijengsci.2011.10.006

${ }^{10}$ Z. C. Ou, Z. P. Duan, F. L. Huang, Analytical approach to the strain rate effect on the dynamic tensile strength of brittle materials, Int. J. Imapct. Eng., 37 (2010) 8, 942-945, doi:10.1016/j.ijimpeng.2010. 02.003

${ }^{11}$ J. Zhu, C. Sun, Z. Qian, The spalling strength of ultra-fiber reinforced cement mortar, Eng. Fail. Anal., 18 (2011) 7, 1808-1817, doi:10.1016/j.engfailanal.2011.05.001 